熱レンズによるベッセルビームの生成*

\author{
ドアン ホン ドク ${ }^{* 1}$, 赤嶺 賢彦*2, 岩谷 直樹 ${ }^{* 2}$ \\ 河野 正道*3, 伏信 一慶 ${ }^{* 1}$
}

\title{
Generation of Bessel Beam by Using Thermal Lens
}

\author{
Hong Duc DOAN ${ }^{* 1}$, Yoshihiko AKAMINE, Naoki IWATANI, Masamichi KOHNO \\ and Kazuyoshi FUSHINOBU
}

${ }^{* 1}$ Tokyo Institute of Technology, Dept. of Mechanical Engineering and Control Engineering Ookayama, Meguro-ku, Tokyo, 152-8552 Japan

Bessel beam has been gaining strong attention from various applications. In this study, a new concept for generating zero-order Bessel beams was studied theoretically and experimentally. The principle of the generation of a Bessel-like beam is discussed based on Fourier optics. A preliminary model is proposed that accounts for heat conduction and diffraction effect. Analytical modeling results indicated that Bessel beam can be generated by using a thermal lens and a convergent lens. A simple and flexible method to convert a Gaussian laser beam into a Bessel-like beam with a long and narrow focal line by using a thermal lens effect is demonstrated experimentally. Experimental and calculated results show a good agreement for generation and characteristics of Bessel-like beam. Experimental results also show that the focal depth of the Bessel beam can be controlled by adjusting some parameters in the thermal lens system. The paper concludes with suggestions for further research and potential applications for the work.

Key Words : Bessel Beam, Thermal Lens Effect, Fluidic Optical Devices

\section{1. 緒言}

Durnin ${ }^{(1)}$ は，自由空間で伝播する際に断面強度分布が伝播距離に依存しない電磁波が存在することを示し， 非回折性ビーム(diffraction-free beam)と名づけた．また，このビームの半径方向の光強度分布がベッセル関数の 二乗で表されることからベッセルビームとも呼ばれている。ベッセルビームは深い焦点深度を有し，かつ自己再 構成（不透明な障害物を通過して完全に再形成することができる）の特性を持つため, 光学的マイクロ操作(2-4) や微細加工 ${ }^{(5-6)}$, ビーム走査顕微鏡 ${ }^{(7-9)}$ などの幅広い分野に応用されている. 微細加工分野においては非常に有用 なベッセルビームの特長を利用した研究はこれまでに幾つか報告された．例えば，松岡らは，ベッセルビームを 用いて, 㛜密な位置および照射パルス数の制御なしに再現性良くテーパの少ないマイクロ穴あけ加工ができるこ とを実証した ${ }^{(5)}$. Marcinkevicius らはフェムト秒レーザを用いてベッセルビームを発生させ, シリカ内の改質加工 を報告した ${ }^{(6)}$. また, 光学的マイクロ操作分野においてはベッセルビームの自己修復性を用いる複数平面での同 時マイクロ操作する研究が報告されている(4).

完全な非回折性ビームは無限大に大きなエネルギーを運ぶため，厳密には実現不可能である。しかし，細い リング開口をつかって，レーザ光をこの近似的非回折性ビームに変換することができる(1). しかし，この方法の

* 原稿受付 2013 年 2 月 14 日

*1 正員, 東京工業大学 (广152-8552 東京都目黒区大岡山 2-12-1)

*2 東京工業大学

*3 正員, 九州大学（广819-0395 福岡県福岡市西区元岡 744)

E-mail:doan.d.aa@m.titech.ac.jp 
変換効率はきわめて低く, 実際には使用されておらず, 現状, アクシコンレンズ(10-11)や Fabry-Perot 干渉計 ${ }^{(12-13)}$, ホログラフィック技術(14)などを用いて高精度なベッセルビームを発生させている．その中でアクシコンレンズを 用いる方法が一番普及している．しかし，アクシコンレンズ，干渉計とホログラムはすべてハイコストかつ固定 光学素子であり, そのために光学システムのパラメーターが固定され, 研究における各パラメーターの検証が困 難である．著者らは熱レンズ効果を用いて，実験と数值計算により液体ビームシェイパ(15)，液体発散レンズ(16)を 提案, 実証した。本研究では, 熱レンズ効果を用いて, ベッセルビームを生成する原理を提案し，モデルと実験 によって原理を検証しながら，光学システムのパラメーターの可変性を示す.

\section{2.＼cjkstart熱レンズによるベッセルビームの生成原理}

\section{$2 \cdot 1$ 環状ビームとベッセルビームの関係}

まずはベッセルビームを発生するDurnin ${ }^{(1)} の$ 最初の実験の原理について説明する. 図1はDurnin ${ }^{(1)} の$ 実験の概略を 示している. 平面波を環状のスリットに照射し, 環状ビームプロファイルを生成する. 環状のスリットが収束レ ンズの後焦点面に位置して，ベッセルビームを生成する. その実験の過程を以下の数式により表現する. 開口面 における電界は以下のように書くことができる.

$$
E_{\text {slit }}=A_{\mathrm{i}} \delta\left(r-r_{\mathrm{s}}\right)
$$

ただし， $A_{\mathrm{i}}$ は波の振幅， $\delta$ はディラックのデルタ関数， $r_{\mathrm{s}}$ はスリット径である. レンズの前焦点面における電界は 入射電界のフーリエ変換に比例しており ${ }^{(17)}$, かつシステムの円形対称性のために, このフーリエ変換はフーリエ ベッセル変換のように書くことができる. そのため, レンズの前焦点面における電界は以下のように書くことが できる.

$$
E_{\text {front }}=\frac{2 \pi}{i \lambda f} \int_{0}^{\infty} r^{\prime} E_{\text {slit }}\left(r^{\prime}\right) J_{0}\left(2 \pi r^{\prime} \rho\right) d r^{\prime}
$$

ただし， $\rho=r / \lambda f, \lambda$ は波長， $f$ はレンズの焦点距離, $J_{0}$ はベッセル関数である. 式(1)を式(2)に代入し，積分を 計算し, 以下の結果が得られる。

$$
E_{\text {front }}=A_{\mathrm{i}} \frac{2 \pi r_{\mathrm{s}}}{i \lambda f} J_{0}\left(\frac{2 \pi r_{\mathrm{s}} r}{\lambda f}\right)
$$

式(3) はゼロ次ベッセルビームの電磁場を表すものである. つまり, ベッセルビームは環状ビームをフーリエ 変換することによって生成される. 実験的には収束レンズがフーリエ変換をする役割を持っている. 過去の研究 により，ガウシアンビームは熱レンズによって環状ビームに変換することが報告された ${ }^{(18)}$.つまり, 熱レンズと 集束レンズを組み合わせることによりベッセルビームを発生させることがきる.

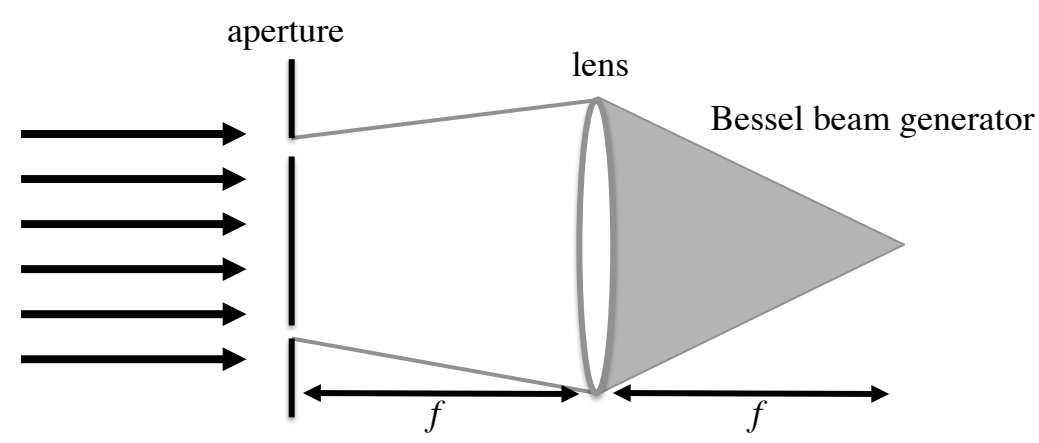

Fig. 1 Schematic illustration of experimental set up for generating a Bessel beam by using an annular aperture and convergent lens 


\section{$2 \cdot 2$ 理論計算による原理の検証}

従来のベッセルビームや熱レンズの研究において, レーザの伝播は定常位相近似のフレネル回折積分によって 解析が行われている. そのために定常位相近似の条件を満たすケースに制限され，加工に用いる高い開口数の対 物レンズにより生成するベッセルビームのような計算は困難である. それで本節のモデルでは，ビーム伝播法を 用いて, ベッセルビームの生成過程をシミュレーションする.

\section{Table 1 Calculation conditions}

\begin{tabular}{ll}
\hline Wave length, $\mathrm{nm}$ & 1070 \\
Power, $\mathrm{W}$ & 7 \\
Focal length, $\mathrm{mm}$ & 114 \\
$\mathrm{M}^{2}$ value & $<1.1$ \\
Beam waist, $\mathrm{mm}$ & 5 \\
Absorption coefficient, $\mathrm{cm}^{-1}$ & 0.23 \\
Distance from cuvette to lens, mm & 450 \\
Thermal conductivity, $\mathrm{W} /(\mathrm{m} \cdot \mathrm{K})$ & 0.167 \\
Density, $\mathrm{kg} / \mathrm{m}^{3}$ & 789 \\
Specific heat, $\mathrm{J} /(\mathrm{kg} \cdot \mathrm{K})$ & 2460 \\
Refractive index change, $\mathrm{d} n / \mathrm{d} T$ & $-3.97 \times 10^{-4}$ \\
\hline
\end{tabular}

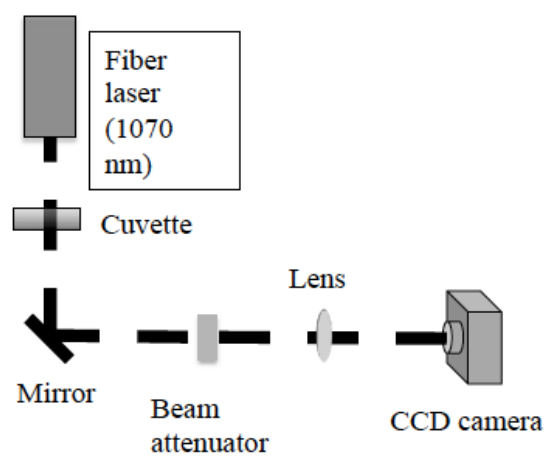

(a) Schematic illustration of the experimental set up

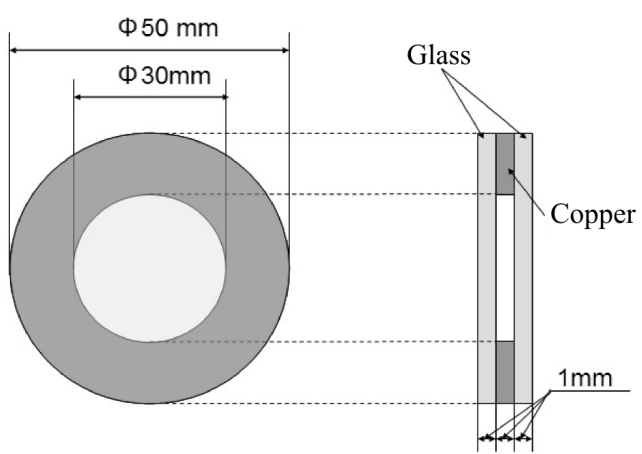

(b) Image picture of cuvette

Fig. 2 Schematic illustration of the experimental set up and calculation model. The beam from a CW fiber laser is focused with a converging lens after passing through a cuvette.

図2は実験の概略図であり，これに基づいて計算モデルを構築した。レーザビームはキュベットを透過し，レー ザ光のエネルギーの一部分はキュベット内の液体に吸収され, 液体の温度場を形成する. 自然対流の影響を無視 できる範囲においてキュベット内の定常状態の温度場は以下の方程式により支配される.

$$
\frac{1}{r} \frac{\partial}{\partial r}\left(r k \frac{\partial T}{\partial r}\right)+\frac{\partial}{\partial z}\left(k \frac{\partial T}{\partial z}\right)+S=0
$$

ただし, $k$ は熱伝導率, Sは生成項である. 生成項はLambert-Beerの法則に従い, 以下の式により求める.

$$
S=\alpha \mathrm{e}^{-\alpha z} I_{0}(r)
$$


ただし, $\alpha$ は吸収係数である. $I_{0}$ は励起レーザの強度分布であり，キュベット厚さ方向の光強度変化は無視できるほ ぞ小さいと仮定している.

キュベット内の液体は温度に比例し屈折率が減少する.レーザビームはその屈折率分布に従い, 集束レンズを 伝播した後自身のプロファイルがガウシアンから環状ビーム, ベッセルビームに変化する.レーザの伝播は以下 のHelmholtz方程式により決定される.

$$
-\frac{\partial^{2} E}{\partial z^{2}}+2 i k_{0} n_{0} \frac{\partial E}{\partial z}=\frac{1}{r} \frac{\partial}{\partial r}\left(\frac{\partial(r E)}{\partial r}\right)+k_{0}^{2}\left(n^{2}-n_{0}^{2}\right) E-\frac{1}{2} i k_{0} n_{0} \alpha E
$$

ただし， $n_{0}$ は室温における液体の屈折率，nはキュベット内の液体の屈折率である. 入射ビームの電場はガウス分 布を持つと仮定し，以下の式により与える.

$$
E=E_{0} \exp \left(\frac{-r^{2}}{r_{0}^{2}}\right)
$$

ただし， $r_{0}$ はビームウェストである．計算に用いるパラメータを表1に示寸.

図3は式(6)で計算した伝播距離によるレーザ強度分布の変化を示している. 図3(a)と(b)はそれぞれ熱レンズが ないとあるときの計算結果である. 座標は半径方向と伝播方向を示し，レーザの強度は任意な単位である. 図 3 (a)より，熱レンズがない時はレーザがガウス分布を維持しながら伝播し，焦点付近で急激にビームウェストを 変化し, 焦点深度が短いことが分かる.また, 図 3 (b) 中の典型的な光強度分布は図 4 に示す. 図 $3(\mathrm{~b})$ より, 熱レ ンズがある時はレーザの強度分布が伝播距離の増加とともに激しく変化し，環状ビームからベッセルビーム（図 4(b)）に変化した後に，再びガウシアンビーム（図4(c)）に戻り，焦点深度も長くなることが分かる.

Table 2 Experimental conditions

\begin{tabular}{ll}
\hline Wave length, $\mathrm{nm}$ & $1070 \pm 10$ \\
Power, W & $1 \sim 100$ \\
Focal length, mm & 114 \\
$\mathrm{M}^{2}$ value & $<1.1$ \\
Beam waist, mm & $4.5 \sim 5.5$ \\
Absorption coefficient, $\mathrm{cm}^{-1}$ & 0.23 \\
Distance from cuvette to lens, $\mathrm{mm}$ & 450 \\
\hline
\end{tabular}

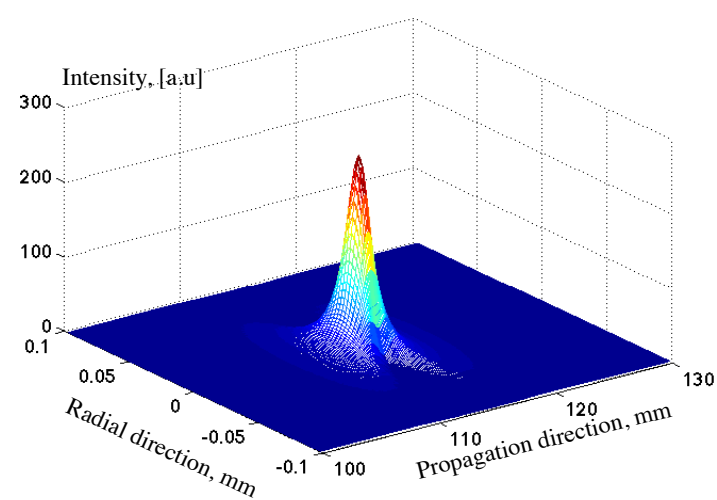

(a) Without thermal lens

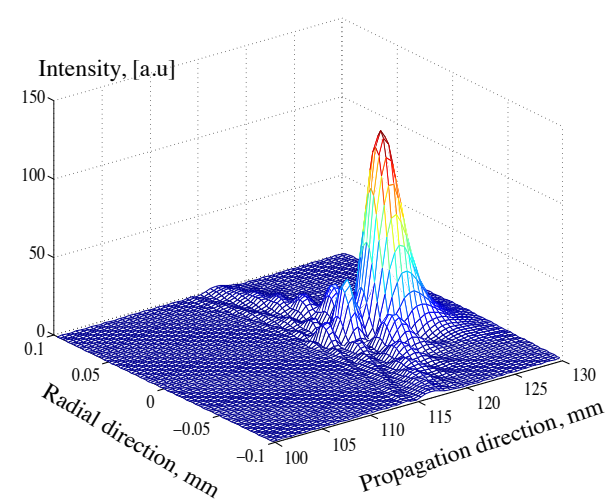

(b) With thermal lens

Fig. 3 Spatial intensity distribution of the probe laser without thermal lens (a) and with thermal lens (b). Along propagation, transverse profile changes from annular to Bessel and Gaussian beam. 


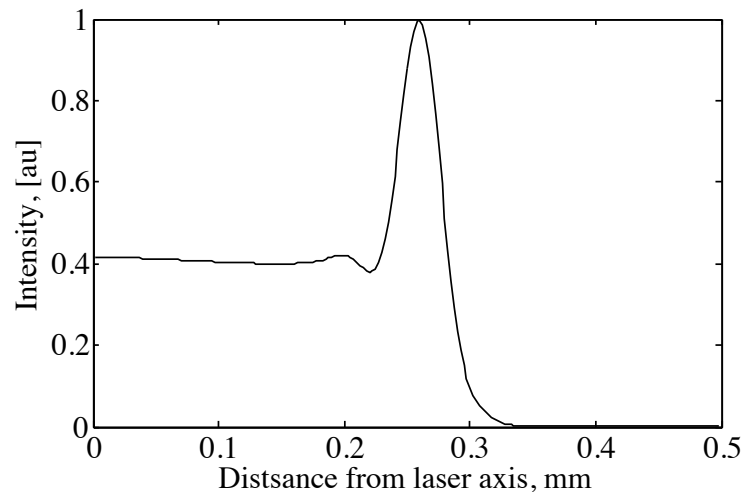

(a) Annular beam, $z=110 \mathrm{~mm}$

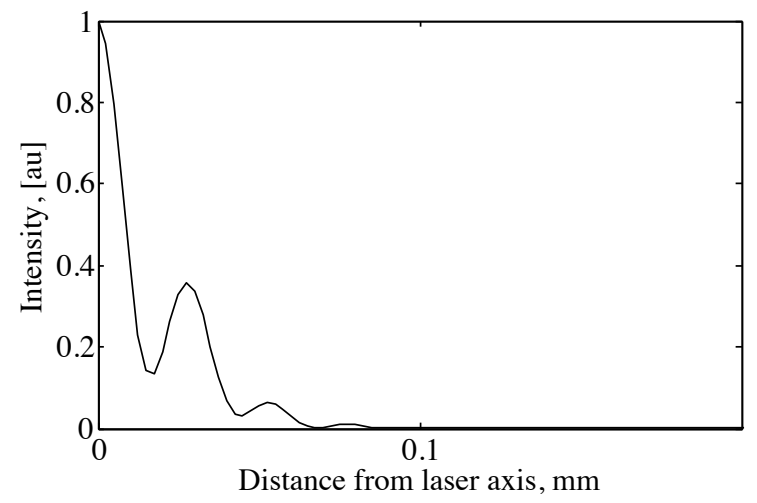

(b) Bessel beam, $z=121 \mathrm{~mm}$

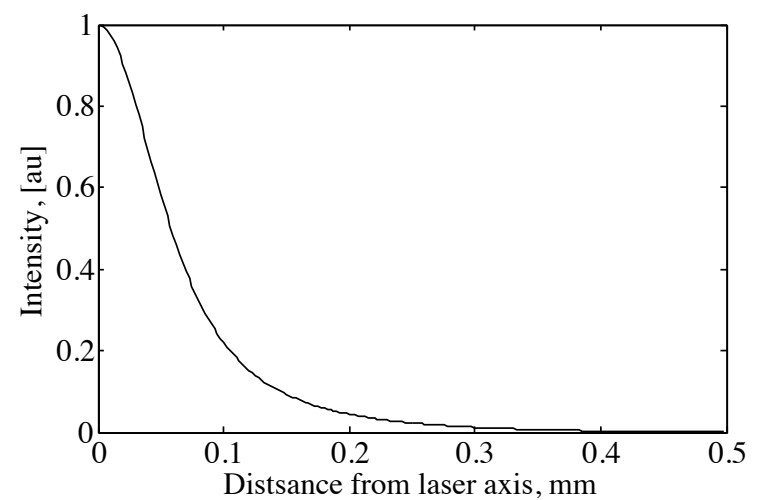

(c) Gaussian beam, $z=130 \mathrm{~mm}$

Fig. 4 Transverse profile of the probe laser at the different distance from the lens. The vertical and horizontal axes show intensity and distance from laser axis respectively. 


\section{3.＼cjkstart実験によるベッセルビームの形成の検証}

\section{$3 \cdot 1$ 実験装置及び実験手法}

図 2 に実験装置の概略図を示す.ファイバーレーザは励起・検出光として用いられる. 現実のレーザ加工への応 用も睨み，本実験の励起・検出は高強度範囲（1 10W）において行う. その際，キュベット内の液体に温度場に起 因する自然対流が発生しビームプロファイルを乱しやすくなるため, 解決策としてキュベット内の液体層の厚さ を薄くし，かつレーザはキュベットの鉛直上方から照射する．キュベットに入射するレーザ強度を調整し，パワ ーメータによって測定する. キュベットを透過したレーザビームは可変連続アッテネータにより強度を減衰させ た上で集束レンズにより集光させる.

キュベットは環状型の銅板を 2 枚のガラス板により挟み, 形成される空洞に液体が注入されている. ガラス板 の厚さは $1 \mathrm{~mm}$ である. 銅板の厚さを変えることで液体層の厚さを調整できる. キュベット内の液体は Sunset Yellow 染料を溶かしたエタノールを用いる. 染料の分子式や代表吸収スペクトルは参考文献 ${ }^{(15)}$ 示す. 本実験で は液体層の厚さが $1 \mathrm{~mm}$, 励起・検出レーザの波長における液体の吸収係数が $0.23 \mathrm{~cm}^{-1}$ （測定值）である.

$\mathrm{CCD}$ カメラは $4 \times$ の拡大レンズを組み, 分解能を $2.5 \times 2.5 \mu \mathrm{m}^{2}$ としている. また, 電動 2 軸ステージ(分解能 $2 \mu \mathrm{m}$ ) により CCD カメラを作動する. まずは熱レンズを外し, CCD カメラをレーザの伝播方向にスキャンし，ビーム中 心の強度を測定する. 伝播軸上の光強度が最大值になる位置がレンズの焦点位置であり,レンズからの $f=114 \mathrm{~mm}$ の位置に決める. その位置を基準とし, 熱レンズが発生する際の光学系の軸上位置を表す. 実験条件 の詳細は表 2 に示す.

\section{$3 \cdot 2$ 実験結果および考察}

図 5 は励起光強度が 7W の時の実験結果であり，伝播軸に沿っている検出レーザの空間強度分布の変化を示した ものである. 図 4 に示す計算結果と同様に, 検出レーザは焦点付近で環状ビーム (図 5(a)) からベッセルビーム (図 5(b)）に変化してからまたガウシアンビーム（図 5(c)）に戻ることが確認できた.また，図 5(b)の実線と点はそれ ぞれ計算結果と実験結果を示している. 計算と実験結果はよく一致し, モデルの妥当性を示した. 計算結果に比 べ，実験に測定したビーム径はやや大きくなり（図 5(b)）またはやや小さくなり（図 5(c)），これらは収束レンズ の収差のためと, $\mathrm{M}^{2}$ のためと考えられる.

図 6 は軸上の光強度の変化を示す. 縦軸と横軸はそれぞれ規格化された光強度と伝播軸上の距離を示している. 図中の四角印と丸印はそれぞれ熱レンズが存在しない場合と存在する場合の軸上の光強度の変化である. 熱レン ズが存在しない場合にはレーザビームの断面空間強度分布がガウス分布を保ったまま伝播し，焦点距離はレイリ 一長さで表される. 一方, 熱レンズが存在する場合の焦点深度を伝播軸上の光強度分布の半值全幅と定義すると, 図のように，焦点距離が長くなり，焦点深度も深くなることが分かる.

図 7 に各励起光強度における焦点深度の実験結果を示す. 縦軸と横軸はそれぞれ焦点深度と励起光強度を示し ている. 励起光強度の増加に伴い, 焦点深度がほぼ線形に増加することが分かる. すなわち, 今回の実験条件の 範囲においては励起光強度や液体の吸収係数，キュベット内の液体層の厚さを調整することにより焦点深度を制 御することができる，ただし，吸収するエネルギーにより液体を相変化させないことに注意する必要がある。実 用上は, 励起光強度の調整が最も容易であると考えられる.

\section{4. 結 語}

本論文では，フーリエ変換を用いて，環状ビームとベッセルビームの関係を示し，熱レンズと収束レンズの組 み合わせによりベッセルビームの発生原理を示した．また，実験と計算により熱レンズシステムにおけるべッセ ルビームの生成が確認し，ベッセルビームの焦点距離や焦点深度と励起光強度の特性を明らかにした。この流体 ビームシェイパはアクシコンレンズなどの一般的な固体ビームシェイパのように複雑な設計過程や製作過程を要 さず，染料，液体，それらを封入するキュベットのみにより作成可能なため，固体ビームシェイパに比べて容易 かつ安価に製作できるという利点があると言える. 


\section{謝 辞}

筆頭著者は日本学術振興会の支援に感謝する. 本研究の一部は，科学研究費補助金（特別研究員奨励費： 23006195）により行われた．また，東京工業大学佐藤・齊藤研究室からファイバーレーザを借用した．ここに謝 意を表する.

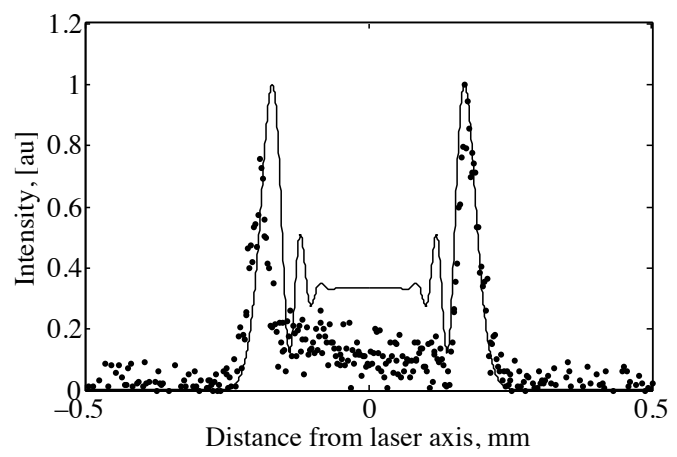

(a) Annular beam, $z=113 \mathrm{~mm}$

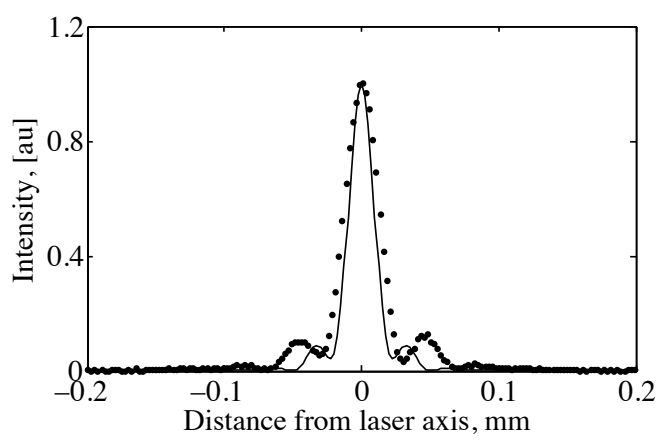

(b) Bessel beam, $z=122 \mathrm{~mm}$

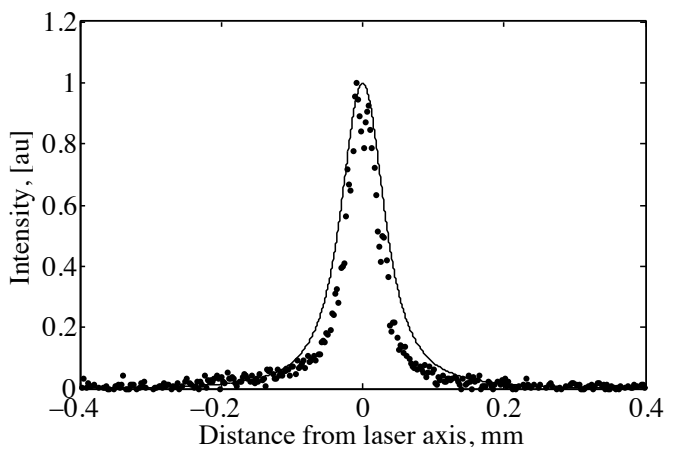

(c) Gaussian beam, $z=128 \mathrm{~mm}$

Fig. 5 Experimental results. Pump power: 7W. Transverse profile of the probe laser changes from annular to Bessel and Gaussian beam along propagation direction. The vertical and horizontal axes show intensity and distance from laser axis respectively. The solid-line and dots are the calculated and experimental results. 


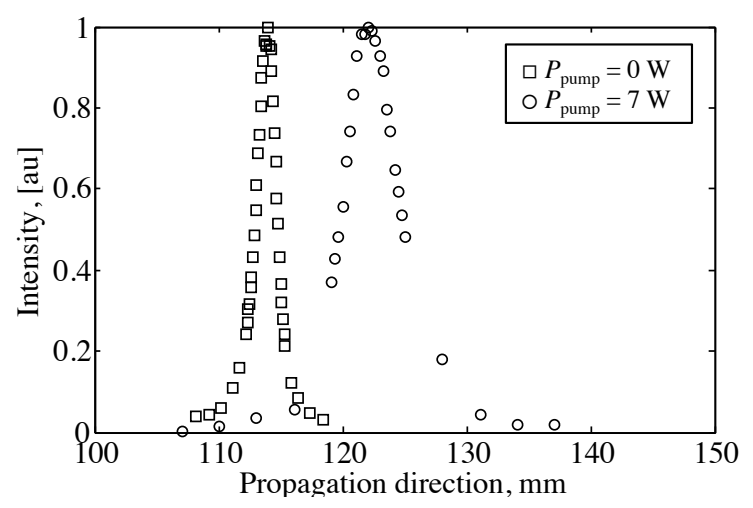

Fig. 6 On-axis intensity of the probe laser. The vertical and horizontal axes show intensity and distance from laser axis respectively. Squares and circles show the on-axis intensity of the probe laser without and with thermal lens effect (pump power: 7W).

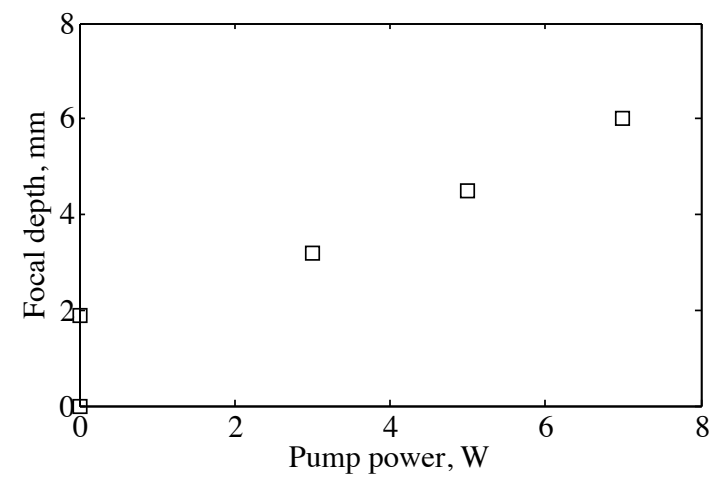

Fig. 7 Relationship between the pump power and the focal depth. The horizontal and vertical axes show pump power and focal depth respectively. Pump power is changed from 3 to $7 \mathrm{~mW}$.

\section{文献}

(1) Durnin, J., "Exact solutions for nondiffracting beams. I. The scalar theory", Journal of the Optical Society of America A, Vol. 4, No. 4 (1987), pp. 651-654.

(2) Florjanczyk, M., and Tremblay, R., "Guiding of atoms in a travelling-wave laser trap formed by the axicon", Optics Communications, Vol. 73, No. 6 (1989), pp. 448-450.

(3) Arlt, J., Garces-Chavez, V., Sibbett, W., and Dholakia, K., “Optical micromanipulation using a Bessel light beam”, Optics Communications, Vol. 197, No. 6903 (2002), pp. 145-147.

(4) Garcés-Chávez, V., McGloin, D., Melville, H., Sibbett, W., and Dholakia, K., "Simultaneous micromanipulation in multiple planes using a self-reconstructing light beam", Nature, Vol. 419, No. 4-6 (2001), pp. 239-245.

(5) Matsuoka, Y., Kizuka, Y., and Inoue, T., "The characteristics of laser micro drilling using a Bessel beam”, Applied Physics A, Vol. 84, No. 4 (2006), pp. 423-430.

(6) Marcinkevicius, A., Juodkazis, S., Matsuo, S., Mizeikis, V., and Misawa, H., "Application of Bessel Beams for Microfabrication of Dielectrics by Femtosecond Laser”, Japanese Journal of Applied Physics, Part 2, Vol. 40, No. 11A (2001), pp. 1197.

(7) Arimoto, R., Saloma, C., Tanaka, T., and Kawata, S., "Imaging properties of axicon in a scanning optical system", Applied Optics, Vol. 31, No. 31 (1992), pp. 6653-6657. 
(8) Ding, Z., Ren, H., Zhao, Y., Nelson, J. S., and Chen, Z., "High-resolution optical coherence tomography over a large depth range with an axicon lens", Optics Letters, Vol. 27, No. 4 (2002), pp. 243-245.

(9) Dufour, P., Pich, M., De Koninck, Y., and McCarthy, N., "Two-photon excitation fluorescence microscopy with a high depth of field using an axicon", Applied Optics, Vol. 45, No. 36 (2006), pp. 9246-9252.

(10) McLeod, J. H., "The axicon: a new type of optical element", Journal of Optical Society of America (1917-1983), Vol. 44, No. 8(1954), pp. 592-592.

(11) Arlt, J., and Dholakia, K., "Generation of high-order Bessel beams by use of an axicon”, Optics Communications, Vol. 177, No. 1-6 (2000), pp. 297-301.

(12) Cox, A. J., and Dibble, D. C., "Nondiffracting beams from a spatially filtered Fabry-Perot resonator", Journal of the Optical Society of America A, Vol. 9, No. 2(1992), pp. 282-286.

(13) Indebetouw, G., "Nondiffracting optical fields: some remarks on their analysis and synthesis", Journal of the Optical Society of America A, Vol. 6, No. 1 (1989), pp. 150-152.

(14) Turunen, J., Vasara, A., and Friberg, A. T., "Holographic gen- eration of diffraction-free beams", Applied Optics, Vol. 27 , No. 19 (1988), pp. 3959-3962.

(15) Goodman, J.W., Introduction to Fourier optics (2005), Roberts and Company.

(16) Power, J. F., "Pulsed mode thermal lens effect detection in the near field via thermally induced probe beam spatial phase modulation: a theory", Applied Optics, Vol. 29, No. 1 (1990), pp. 52-63.

(17) Doan, H. D., Akamine, Y., Fushinobu, K., "Fluidic laser beam shaper by using thermal lens effect", International Journal of Heat and Mass Transfer, Vol. 55, No. 11-12 (2012), pp. 2807-2812.

(18) Doan, H. D., Akamine, Y., Fushinobu, K., "Fluidic lens by using thermal lens effect", International Journal of Heat and Mass Transfer, Vol. 55, No. 23-24 (2012), pp. 7104-7108. 